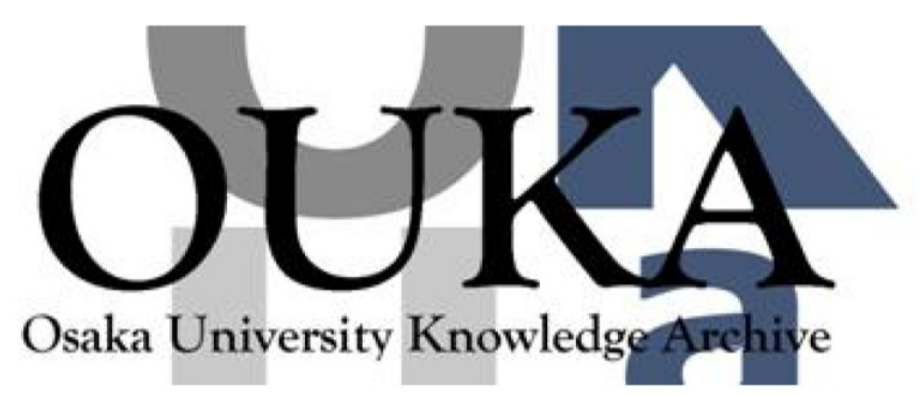

\begin{tabular}{|c|c|}
\hline Title & $\begin{array}{l}\text { Conformational change from rigid rod to star: A } \\
\text { triple-helical peptide with a linker domain at } \\
\text { the c-terminal end }\end{array}$ \\
\hline Author(s) & $\begin{array}{l}\text { Terao, Ken; Mizuno, Kazunori; Bächinger, Hans } \\
\text { Peter }\end{array}$ \\
\hline Citation & $\begin{array}{l}\text { Journal of Physical Chemistry B. 119(9) p.3714- } \\
\text { p. } 3719\end{array}$ \\
\hline Issue Date & $2015-02-16$ \\
\hline oaire:version & AM \\
\hline URL & https://hdl. handle. net/11094/81831 \\
\hline rights & $\begin{array}{l}\text { This document is the Accepted Manuscript } \\
\text { version of a Published Work that appeared in } \\
\text { final form in Journal of Physical Chemistry B, } \\
\text { o American Chemical Society after peer review } \\
\text { and technical editing by the publisher. To } \\
\text { access the final edited and published work see } \\
\text { https://doi.org/10.1021/jp5129172. }\end{array}$ \\
\hline Note & \\
\hline
\end{tabular}

Osaka University Knowledge Archive : OUKA

https://ir. Library. osaka-u. ac. jp/

Osaka University 


\title{
Conformational Change from Rigid Rod to Star: A Triple Helical Peptide with a Linker Domain at the C- terminal End
}

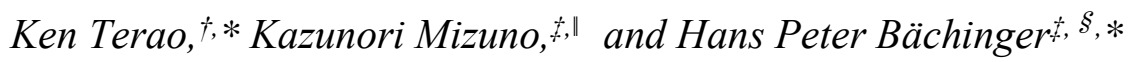

†Department of Macromolecular Science, Osaka University, 1-1, Machikaneyama-cho, Toyonaka, Osaka, 560-0043, Japan, *Research Department, Shriners Hospital for Children, Portland, Oregon 97239, and ${ }^{\S}$ Department of Biochemistry and Molecular Biology, Oregon Health \& Science University,

Portland, Oregon 97239

* Corresponding Authors. E-mail: kterao@chem.sci.osaka-u.ac.jp,hpb@shcc.org

" Present Address. Nippi Research Institute of Biomatrix, 520-11 Kuwabara, Toride, Ibaraki 302-0017, Japan

ABSTRACT: Small-angle X-ray scattering and circular dichroism measurements were made for a triple helical peptide of which one end was linked by the thermally stable trimerization domain of type XIX collagen. The radius of gyration decreased steeply around the transition temperature while the scattering intensity at zero angle did not significantly change, indicating no molar mass change through the conformational transition. Thus, the data were analyzed in terms of the rigid cylinder model for the data at low temperatures and the wormlike star model at high temperatures. It was confirmed that the peptide molecules behave as a rod-like cylinder at low temperature and a semi flexible three-arm starlike chain at high temperature of which the single-coil peptide chain is appreciably extended by the high segment density nearby the linking domain.

\section{- INTRODUCTION}

Global conformations of synthetic polymers and some linear biopolymers, e.g. linear polysaccharides and DNA, are mainly observed by light and small-angle X-ray (or neutron) scattering and some other methods. The obtained structural data are well analyzed by the wormlike $\operatorname{chain}^{1}$ (or more generally, the helical wormlike chain $\left.{ }^{2-3}\right) \cdot{ }^{4-5}$ On the contrary, ternary structures of protein molecules are usually determined from X-ray diffraction as well as multi-dimensional NMR spectroscopy since thermal fluctuation is not significant for their structure, which is mainly stabilized by $\alpha$-helices and $\beta$-sheets, and hence their internal rotation of the main chain is mostly determined by the non-covalent-bond interactions, that is, hydrogen bonds and hydrophobic interactions. While NMR and diffraction methods are suitable to determine such tightly folded portions, actual dimensions of 'random coil' portions in the peptide seem not be considered as very important. This is because such important functions of proteins are mainly related with the tightly-folded local atomic-scale structure than the average conformation of random coil parts. However, rather flexible regions including sugar chains are often not negligible to understand the structure-function relationship. Indeed, such flexible regions of some peptide molecules have significant function. ${ }^{6}$ The length of 'random coil' parts of peptides are however not long enough to treat as Gaussian coil since many completely denatured proteins have a finite chain stiffness, that is, the Kuhn segment length of $\sim 2 \mathrm{~nm} .^{7-8}$ This value is close to those for typical vinyl polymers. ${ }^{2}$ Furthermore, conformation of 'random coil' parts should be affected by the folded domains; indeed, gyration radii of both randomly ${ }^{9-12}$ and regularly ${ }^{13}$ branched comb polymers are appreciably larger than that predicted for the Gaussian comb chain even in the theta solvent. To clarify the conformational behavior of peptide chains nearby the folded domain, investigation of dimensional properties of rather simple peptides with no molar mass distribution should be useful. Thus, we chose a triple helical peptide having a transition temperature nearby room temperature and one end fixed by a domain which has high temperature stability as illustrated in Figure 1. ${ }^{14-16}$ These kinds of peptides are used to investigate thermal stability as well as kinetics of triple helical native collagen sequences. Thus, 
we made small-angle X-ray scattering as well as circular dichroism measurements for the peptide in aqueous media at different temperatures.

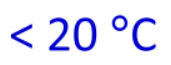

$(\mathrm{GPP})_{7} \mathrm{XIX} \mathrm{NC2}$

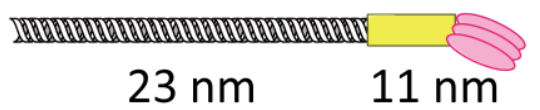

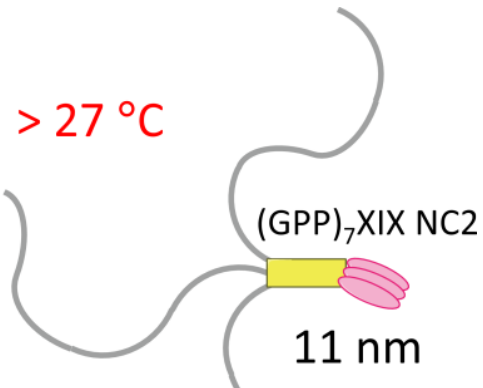

$11 \mathrm{~nm}$

Figure 1. Schematic representation of the peptide sample in the aqueous buffer.

\section{- EXPERIMENTAL SECTION}

Preparation of the Peptide Sample. The human cDNA clone of COL2A1 IRCFp5008C071D was purchased from imaGenes G0mbH (Berlin, Germany). The fragment, residues 712-792 of the major triple helical region of type II collagen was PCR amplified using two oligonucleotides 5' - ATA GGA TCC GGC AAC CCT GGA CCC CCT G -3' (forward primer, the BamHI site is underlined) and 5'TAT GGG CCC TCT CTC ACC ACG TTG CCC AGG -3' (reverse primer, the ApaI site is underlined). The amplified DNA was inserted into the host pET23 vector as 6xHis tag-thioredoxin-thrombin cleavage site-(ApaI)-type II collagen-(BamHI)-(GPP) ${ }_{7}-\mathrm{NC} 2$ domain of type XIX collagen vector ${ }^{16}$ Type XIX collagen NC2 trimerization domain containing the last COL2 domain tripeptide Gly-Ile-Pro (residues 1007 to 1040 of collagen type XIX human protein, accession number CAI42716 version CAI42716.1 GI:57208771). The exact protein sequence attached after (GPP) 7 repeat is GIPADAVSFEEIKKYINQEVLRIFEERMAVFLSQ. The final sequence of the fusion protein after thrombin cleavage is shown in Figure 2. The DNA sequence of the plasmid was verified by Sanger dideoxy DNA sequencing.

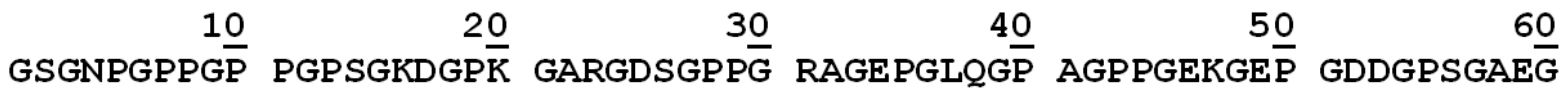

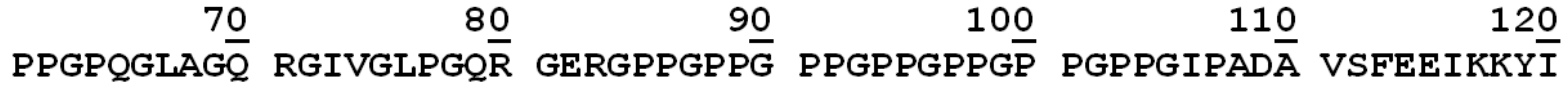

\section{0 \\ NQEVLRIFEE RMAVFLSQ}

Figure 2. Amino acid seqeuce of the peptide investigated in this study.

The recombinant protein was expressed at $15^{\circ} \mathrm{C}$ in the E.coli BL21 (DE3) host strain (Invitrogen) after isopropyl $\beta$-D-1-thiogalactopyranoside induction (final concentration $1 \mathrm{mM}$ ) for 2 days in two flasks with $500 \mathrm{~mL}$ 2xTY media. Cells were chilled and harvested by centrifugation, lysed by ultrasonication and the soluble material was precipitated with saturated solution of ammonium sulfate. Further, the expressed proteins were purified by HiTrap ${ }^{\mathrm{TM}}$ chelating HP column (GE Healthcare Life sciences) with immobilized nickel ion. The His-thioredoxin tag fragment was cleaved by thrombin with $1 \mathrm{U} / \mathrm{mL}$ (BD BaculoGoldTM BD Biosciences) in $40 \mathrm{mM}$ Tris/HCl buffer, $\mathrm{pH} \mathrm{8.2,} \mathrm{containing} 150 \mathrm{mM}$ $\mathrm{NaCl}$ on ice. The resulting fragments had two additional amino acid residues GS before the natural type II collagen sequence. After thrombin cleavage, the protein solutions were treated with $1 \mathrm{mM}$ diisopropyl fluorophosphate for $3 \mathrm{~h}$ on ice to inactivate proteinases. Then, the solutions were applied to a HisTrap ${ }^{\mathrm{TM}}$ HP column to remove the His-thioredoxin tag. The natural type II collagen fragment with 
the trimerization knot was eluted with approximately $10-20 \mathrm{mM}$ imidazole. After the addition of $0.05 \%$ Tween 20, the protein solutions were dialyzed against $50 \mathrm{mM} \mathrm{NaCl}, 20 \mathrm{mM}$ HEPES pH 7.35, and purified with a $5 \mathrm{~mL}$ volume of SP Sepharose Fast Flow column (GE Healthcare Life sciences). The fractions were collected using a step $\mathrm{NaCl}$ gradient. The fractions with the pure protein $(150-200 \mathrm{mM}$ $\mathrm{NaCl}$ ) were dialyzed and concentrated in $200 \mathrm{mM} \mathrm{NaCl}, 20 \mathrm{mM}$ Tris/ $\mathrm{HCl}, \mathrm{pH} 7.0$ for further analysis. The peptide concentration was determined by amino acid analysis to be $0.28 \mathrm{mg} \mathrm{cm}^{-3}$.

Small-angle X-ray scattering (SAXS). Small-angle X-ray scattering measurements were made for the peptide sample in the buffer at the BL40B2 beamline in SPring-8 (Hyogo, Japan) and at the BL10C beamline in KEK-PF (Ibaraki, Japan). The wavelength $\lambda_{0}$ and the camera length were set to be $0.10 \mathrm{~nm}$ (SPring-8) - $0.15 \mathrm{~nm}$ (KEK-PF) and $4000 \mathrm{~mm}$ (SPring-8) - $2000 \mathrm{~mm}$ (KEK-PF), respectively. The original solution and three diluted solutions having different peptide mass concentration $c$ were measured in $2 \mathrm{~mm}$ quartz capillary at $5{ }^{\circ} \mathrm{C}, 15{ }^{\circ} \mathrm{C}, 20^{\circ} \mathrm{C}, 23{ }^{\circ} \mathrm{C}, 25{ }^{\circ} \mathrm{C}, 27{ }^{\circ} \mathrm{C}, 30{ }^{\circ} \mathrm{C}, 40{ }^{\circ} \mathrm{C}$, and $50{ }^{\circ} \mathrm{C}$ and the scattered light was detected by using a RIGAKU R-AXIS VII imaging plate detector. The magnitude of the scattering vector $q$ at each pixel on the imaging plate was determined from the Bragg diffraction peak of powder silver behenate. The scattering intensity $I(q)$ at each $q$ was obtained from the circularly average method. The excess scattering intensity $\Delta I(q)$ of each solution was estimated from the difference of $I(q)$ for the solution and the solvent in the same capillary. It should be noted that the concentration dependence of $c / \Delta I(q)$ was negligibly small and thus the data for the highest concentration were used in the following analysis to minimize signal-noise ratio.

Circular Dichroism (CD). CD spectra were recorded on a Jasco J720WO spectropolarimeter with a Peltier thermostated cell holder and a quartz cell of $1 \mathrm{~mm}$ path length. Thermal scanning curves were recorded at $223 \mathrm{~nm}$ and at $6 \mathrm{~K} \mathrm{~h}^{-1}$.

\section{- RESULTS AND DISCUSSION}

Temperature Dependence of the Helix Content. Figure 3 illustrates the temperature course of the ellipticity $\theta_{223}$ for the peptide sample in buffer $(200 \mathrm{mM} \mathrm{NaCl}, 20 \mathrm{mM}$ Tris-HCl $\mathrm{pH} 7.0)$ at $\lambda_{0}=223$ $\mathrm{nm}$. This ellipticity remarkably reflects the secondary structure of polypeptides and therefore it is frequently used to determine the helix content of the triple helical structure. ${ }^{17}$ The measured $\theta_{223}$ decreases steeply with raising temperature in between $20^{\circ} \mathrm{C}$ and $24{ }^{\circ} \mathrm{C}$, suggesting that the triple helical structure of the N-terminal type II collagen unit unwinds to random coil in this temperature range, and hence the whole shape of the trimeric peptide changes from rodlike to star-like chains as illustrated in Figure 1. Furthermore, a slight but appreciable decrease is seen between $55{ }^{\circ} \mathrm{C}$ and $60{ }^{\circ} \mathrm{C}$. This is likely due to denaturation of the triple helix of the $(\mathrm{GPP})_{7}$ part (yellow domain in Figure 1). This is reasonable because the $(\mathrm{GPP})_{7}$ part chain of $(\mathrm{GPP})_{7} \mathrm{NC} 2$ has a conformational transition around $50{ }^{\circ} \mathrm{C} .{ }^{14}$ Anyway, $\theta_{223}$ at lower than $20^{\circ} \mathrm{C}$ and in between $25^{\circ} \mathrm{C}$ and $50{ }^{\circ} \mathrm{C}$ obeys a straight line, indicating no conformational change in these temperature ranges. Thus we may estimate the helix content $F(T)$ of the first 83 residues by

$$
\theta(T)=F(T) \theta_{\text {helix }}(T)+[1-F(T)] \theta_{\text {coil }}(T)
$$

as a function of temperature $T$. The transition temperature estimated from this method was substantially the same as that from differential calorimetry for some similar peptides. ${ }^{15}$ It should be noted that the dielectric relaxation method reported by Shikata et al. ${ }^{18}$ might not be suitable for the current system since the current peptide molecules consists of a number of ionic amino acids as shown in Figure 2. 


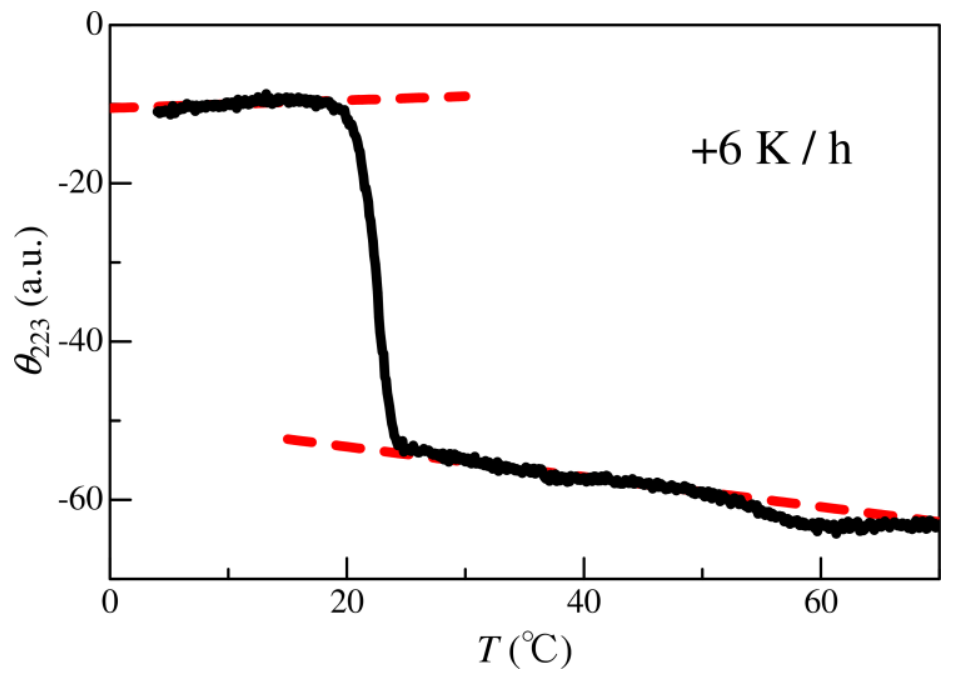

Figure 3. Temperature dependence of ellipticity $\theta_{223}$ at $\lambda_{0}=223 \mathrm{~nm}$ for the peptide sample in $200 \mathrm{mM}$ $\mathrm{NaCl}, 20 \mathrm{mM}$ Tris- $\mathrm{HCl} \mathrm{pH}$ 7.0. Heating rate was $6 \mathrm{~K} / \mathrm{h}$.

Berry Plots and the Gyration Radius. Figure 4 shows the Berry plots ${ }^{19}$ for the peptide at the temperatures between $5{ }^{\circ} \mathrm{C}$ and $40{ }^{\circ} \mathrm{C}$. The excess scattering intensity $\Delta I(q)$ is related to the molar mass $M$ of the trimeric peptide and the excess electron density $\Delta z$ as $^{20}$

$$
\left[\frac{K \Delta z^{2} c}{\Delta I(q)}\right]^{\frac{1}{2}}=\frac{1}{M^{\frac{1}{2}}}\left(1+\frac{1}{6}\left\langle S^{2}\right\rangle q^{2}\right)
$$

where $K$ is the optical constant, which is independent from temperature. Temperature change of $\Delta z$ was estimated from the density of the buffer solution at each temperature assuming that temperature dependence of the partial specific volume of the peptide is negligibly small in the range of temperatures investigated. These data were acquired at the same beamline, capillary cell, and the date. Thus, the $K$ value should be the same for the data in this figure. This Berry plot is suitable both for rodlike and flexible chains ${ }^{19,21}$ and indeed used for the analysis of star polymers ${ }^{22}$ in solution. While the data points at $20^{\circ} \mathrm{C}$ and lower temperatures have a larger initial slope than those at higher temperatures, a common intercept ( 17) is found, indicating that the molar mass of the trimeric peptide does not change with the conformational change of the native type II collagen domain. Thus, we may conclude that the $(\mathrm{GPP})_{7} \mathrm{NC} 2$ domain keeps the trimer structure in this temperature range. The measured radius of gyration $<S^{2}>1 / 2$ from the initial slope of Figure 4 is $9.5-10.3 \mathrm{~nm}$ below $20{ }^{\circ} \mathrm{C}$. These values are close to $9.8 \mathrm{~nm}$ calculated by $12^{-0.5} L$ with the length of cylinder $L$ being $34 \mathrm{~nm}$, which was estimated from the amino acid sequence and circular dichroism. ${ }^{14}$ It should be noted that though the bond angle $\theta$ between the NC2 domain and triple helical GPP7 domain is different from $180^{\circ}$ as shown in Figure 1, the radii of gyration are estimated from $\left\langle S^{2}\right\rangle^{1 / 2}=\left(L_{1}+L_{2}\right)^{2} / 12-\left[L_{1}^{2} L_{2}{ }^{2}(1-\cos \theta)\right] /\left[2\left(L_{1}+L_{2}\right)^{2}\right]$ with $L_{1}(=29$ $\mathrm{nm})$ and $L_{2}(5 \mathrm{~nm})$ being the chain lengths of the two part chains to be $9.75 \mathrm{~nm}$ and $9.68 \mathrm{~nm}$ for $\theta=$ $150^{\circ}$ and $135^{\circ}$, respectively; thus this kink effect should be negligibly small for the current peptide molecule. On the other hand, $<S^{2}>1 / 2$ above $25^{\circ} \mathrm{C}$ is estimated to be around $6.7 \mathrm{~nm}$ depending slightly on temperature. This is reasonable because $\left\langle S^{2}\right\rangle^{1 / 2}$ for random coil of some linear collagen model peptides at $75{ }^{\circ} \mathrm{C}$ is slightly smaller than that at $15{ }^{\circ} \mathrm{C} .{ }^{7}$ 


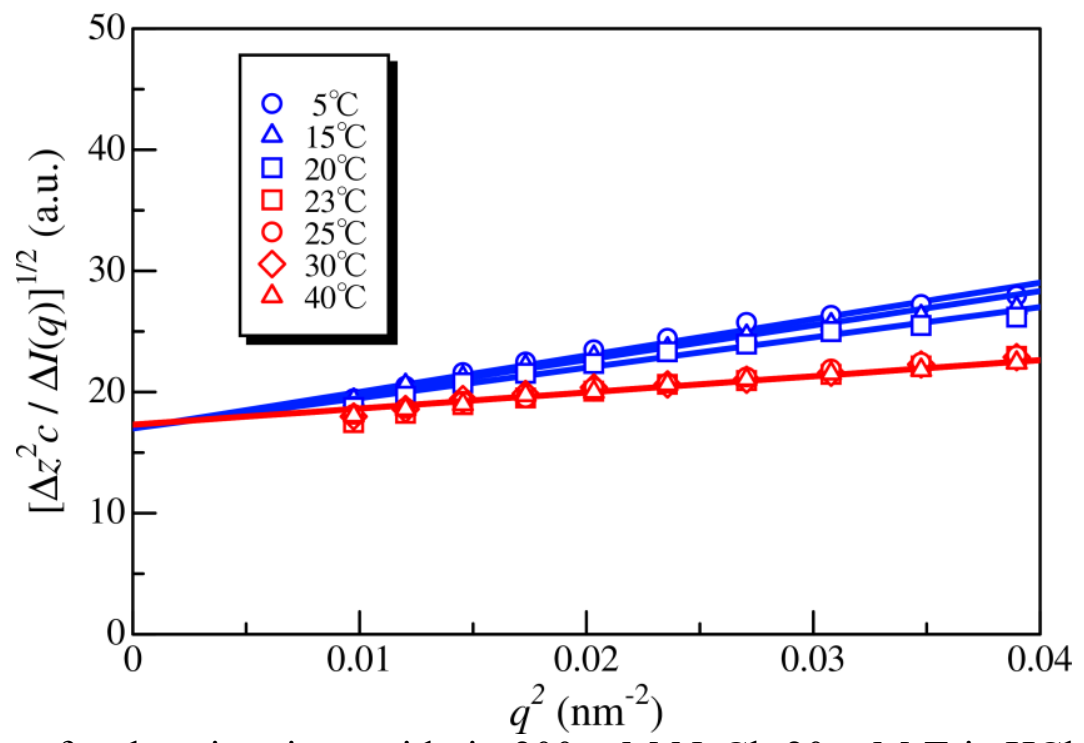

Figure 4. Berry plots for the trimeric peptide in $200 \mathrm{mM} \mathrm{NaCl}, 20 \mathrm{mM}$ Tris- $\mathrm{HCl} \mathrm{pH} 7.0$ at indicated temperatures.

The radius of gyration $\left\langle S^{2}>^{1 / 2}\right.$ is plotted against temperature with the helix content $F(T)$ as shown in Figure 5. The obtained $\left\langle S^{2}>1 / 2\right.$ value decreases rapidly in between $20^{\circ} \mathrm{C}$ and $25^{\circ} \mathrm{C}$ mostly along with the change of $F(T)$, indicating that the temperature change of the chain dimensions is consistent with the change of the local conformation detected by circular dichroism. Thus, the scattering function $P(q)$ at each temperature was analyzed in terms of the rodlike cylinder at lower temperatures and wormlike stars at higher temperatures as described below.

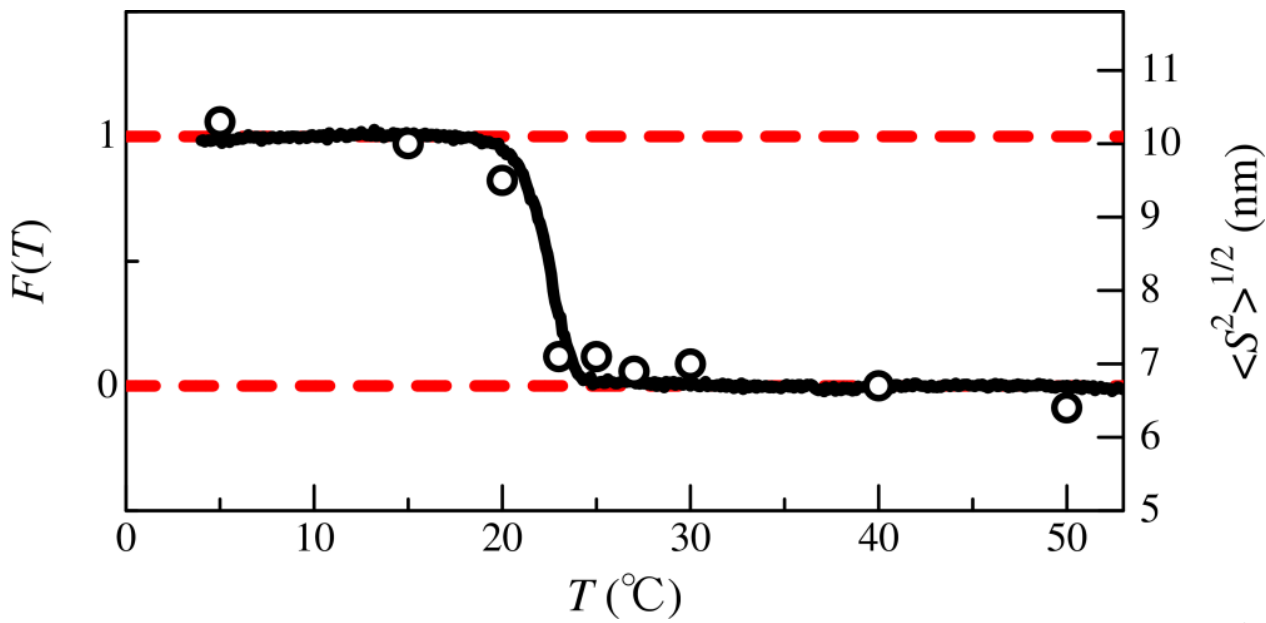

Figure 5. Temperature dependence of the helix content $F$ and the radius of gyration $<S^{2}>^{1 / 2}$ in $200 \mathrm{mM}$ $\mathrm{NaCl}, 20 \mathrm{mM}$ Tris-HCl pH 7.0.

Particle Scattering Function. Figure 6 displays the Holtzer plots ${ }^{23}$ for the peptide in $200 \mathrm{mM}$ $\mathrm{NaCl}, 20 \mathrm{mM}$ Tris- $\mathrm{HCl} \mathrm{pH} 7.0$ at 9 temperatures. At the three lower temperatures, $5{ }^{\circ} \mathrm{C}, 15^{\circ} \mathrm{C}$, and 20 ${ }^{\circ} \mathrm{C}$, they have a so-called Holtzer plateau at low $q$ region reflecting a rod-like conformation. The theoretical particle scattering function $P_{\text {cylinder }}(q)$ for the rigid cylinder is written as ${ }^{24-25}$

$$
P_{\text {cylinder }}(q)=\frac{2 q L \operatorname{Si}(q L)+2 \cos (q L)-2}{(q L)^{2}}\left[\frac{2 J_{1}(q d / 2)}{q d / 2}\right]^{2}
$$

where $J_{1}(x), \operatorname{Si}(x)$, and $d$ are the Bessel function of the first order, the sine integral, and the diameter of the cylinder, respectively. Indeed, the data can be well explained by the solid blue lines calculated for a 
rigid cylinder having the length $L$ of $35 \mathrm{~nm}$ and the diameter $d$ of $1.6 \mathrm{~nm}$. These parameters are comparable with $\left\langle S^{2}>\right.$ of $10 \mathrm{~nm}$. This indicates that the current peptide molecule behaves as rigid rod bellow $20{ }^{\circ} \mathrm{C}$. On the other hand, $P(q)$ at higher temperatures have an appreciable peak at the low- $q$ region, suggesting the existence of star-like peptide chains.

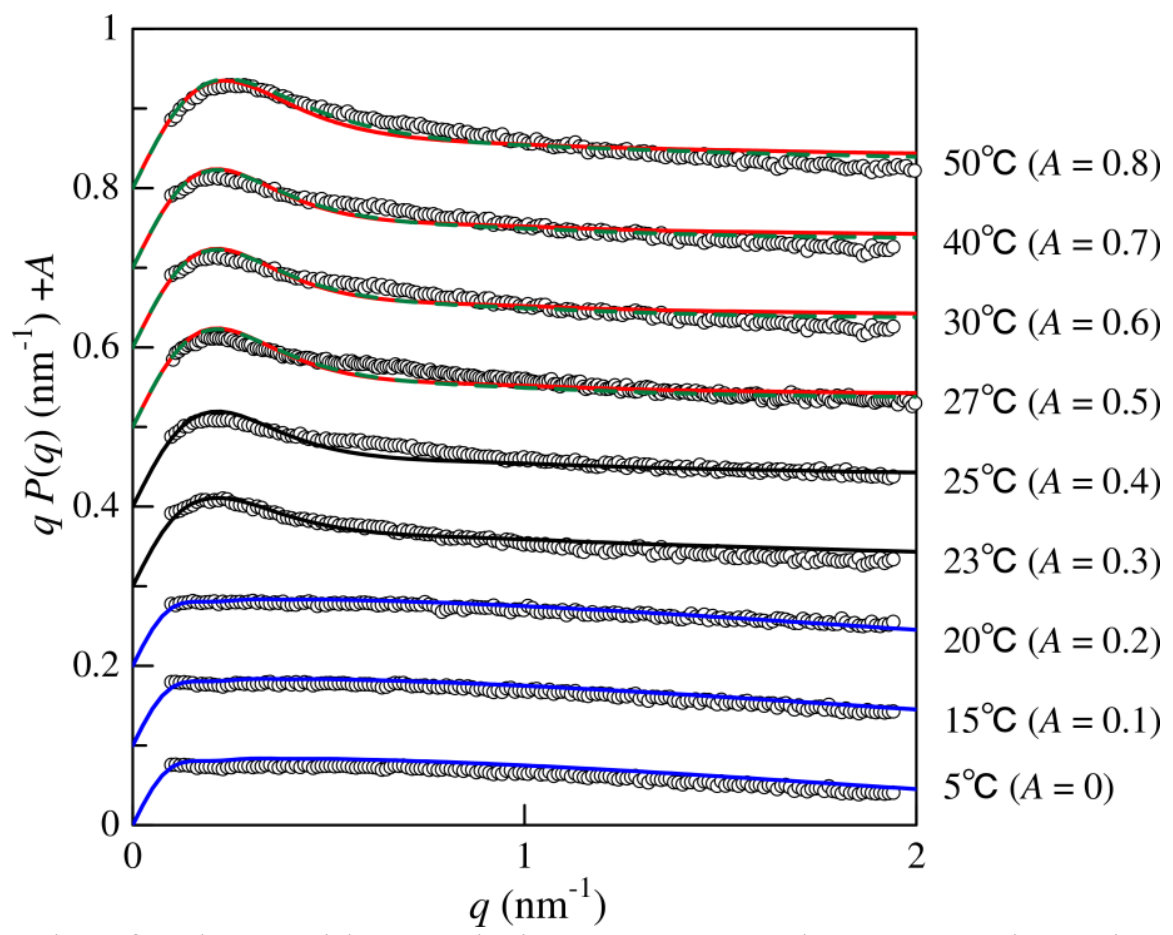

Figure 6. Holtzer plots for the peptide sample in $200 \mathrm{mM} \mathrm{NaCl}, 20 \mathrm{mM}$ Tris- $\mathrm{HCl} \mathrm{pH} 7.0$ at indicated temperatures. The solid blue curves, dashed green curves, solid red curves, and solid black curves, are theoretical values for the rigid cylinder (eq 3), the wormlike star (eq 4 with eq 6), the hetero-star (eq 8 with eq 6), and the mixture of rigid cylinder and hetero-star (eq 9), respectively. See text for the model parameters. The ordinate values are shifted by $A$ for clarity.

According to Huber and Burchard, ${ }^{26}$ the particle scattering function $P_{\text {star,Bw }}(q)$ for the broken threearm wormlike star of which the three chain ends of the three wormlike arms are linked with a universal joint is written as

$$
P_{\mathrm{star}, \mathrm{BW}}(q)=\frac{2\left[\int_{0}^{L_{\mathrm{s}}}\left(L_{\mathrm{s}}-t\right) I\left(\lambda^{-1} q ; \lambda t\right) d t+\left(\int_{0}^{L_{\mathrm{s}}} I\left(\lambda^{-1} q ; \lambda t\right) d t\right)^{2}\right]}{3 L_{\mathrm{s}}^{2}}
$$

where $L_{\mathrm{s}}$ is the contour length of each side chain and $I\left(\lambda^{-1} q ; \lambda t\right)$ is the characteristic function of the wormlike chain, which can be calculated by using the Nakamura-Norisuye approximate expression. ${ }^{25,27}$ Likewise, the particle scattering function $P_{\text {star,CR }}(q)$ for the continuous three-arm wormlike star of which a wormlike side chain with the contour length $L_{\mathrm{s}}$ is linked to the center of the main chain having a contour length $2 L_{\mathrm{s}}$ with a universal joint can be expressed as

$P_{\mathrm{star}, \mathrm{CR}}(q)=\frac{2\left[\int_{0}^{L_{\mathrm{s}}}\left(L_{\mathrm{s}}-t\right) I\left(\lambda^{-1} q ; \lambda t\right) d t+\int_{0}^{2 L_{\mathrm{s}}}\left(2 L_{\mathrm{s}}-t\right) I\left(\lambda^{-1} q ; \lambda t\right) d t+\int_{0}^{2 L_{\mathrm{s}}} I\left(q ;\left|L_{\mathrm{s}}-t\right|\right) d t \int_{0}^{L_{\mathrm{s}}} I\left(\lambda^{-1} q ; \lambda t\right) d t\right]}{9 L_{\mathrm{s}}^{2}}$ 
The effect of chain thickness can be considered by using the following expression for the touched bead chain $^{28}$ with the diameter $d$ as

$$
P(q)=9\left(\frac{2}{q d}\right)^{6}\left(\sin \frac{q d}{2}-\frac{q d}{2} \cos \frac{q d}{2}\right)^{2}\left[P_{\mathrm{star}, \mathrm{BW}}(q) \text { or } P_{\mathrm{star}, \mathrm{CR}}(q)\right]
$$

If we assume the first 83 type II collagen residues behave as random coil at high temperature and we choose the contour length per residue $h$ of $0.33 \mathrm{~nm}$ (or $L_{\mathrm{s}}=83 \times 0.33 \mathrm{~nm}$ ), ${ }^{7}$ the Kuhn segment length ( $\lambda^{-1}$, the chain stiffness parameter) and the chain diameter $d$ were estimated to be $4.5 \mathrm{~nm} \pm 0.5 \mathrm{~nm}$ (or $3.5 \mathrm{~nm} \pm 0.5 \mathrm{~nm}$ at $50^{\circ} \mathrm{C}$ ) and $0.5 \mathrm{~nm} \pm 0.2 \mathrm{~nm}$, respectively. The resultant theoretical dashed green curves in Figure 6 fairly reproduce the experimental data at $27^{\circ} \mathrm{C}, 30^{\circ} \mathrm{C}, 40{ }^{\circ} \mathrm{C}$, and $50{ }^{\circ} \mathrm{C}$. It should be noted that the theoretical curves both calculated from eqs 4 and 5 are substantially the same for the current parameters, suggesting that the initial tangent of side chains of the star wormlike chain does not cause an appreciable difference in $P(q)$ for the current peptide. The radius of gyration of the 3-arm broken wormlike star can be expressed as ${ }^{29}$

$$
\lambda^{2}\left\langle S^{2}\right\rangle=\frac{7 \lambda L_{\mathrm{s}}}{18}-\frac{5}{12}+\frac{3-2 e^{-2 \lambda L_{\mathrm{s}}}}{12 \lambda L_{\mathrm{s}}}-\frac{1-e^{-2 \lambda L_{\mathrm{s}}}}{24 \lambda^{2} L_{\mathrm{s}}^{2}}
$$

If we choose $h=0.33 \mathrm{~nm}$ and $\lambda^{-1}=4.5 \mathrm{~nm}$, the resultant $\left\langle S^{2}>^{1 / 2}\right.$ is calculated to be $6.35 \mathrm{~nm}$, which is slightly smaller than the experimental value $(6.7 \pm 0.3 \mathrm{~nm})$. It should be noted that the bond angle of the junction point is negligible to $\left\langle S^{2}>^{1 / 2}\right.$ for the current peptide of which $1 / \lambda L$ is 0.055 (or $2 a / L$ in the reference). ${ }^{29}$ If assuming the slight temperature dependence of $\left\langle S^{2}>^{1 / 2}\right.$ is only due to the chain stiffness, the parameter $\lambda^{-1}$ estimated at $50^{\circ} \mathrm{C}$ is about $20 \%$ smaller than that at $30{ }^{\circ} \mathrm{C}$. Similar temperature changes were also found for some polymers. ${ }^{30-32}$

In the present case, the center domain (GPP) 7 XIX NC2 seems not to be negligibly small. Therefore, the peptide at high temperature should be better modeled by a heteroarm star with three wormlike arms with contour length $L_{\mathrm{s}}$ and a rodlike arm with the length $L_{\mathrm{r}}$. The particle scattering function $P_{\text {heterostar }}(q)$ for the heteroarm star may be calculated from ${ }^{33}$

$$
P_{\text {heterostar }}(q)=\frac{2\left[3 \int_{0}^{L_{\mathrm{S}}}\left(L_{\mathrm{s}}-t\right) I\left(\lambda^{-1} q ; \lambda t\right) d t+3\left(\int_{0}^{L_{\mathrm{s}}} I\left(\lambda^{-1} q ; \lambda t\right) d t\right)^{2}+\frac{3 \rho_{\mathrm{r}} \operatorname{Si}\left(q L_{\mathrm{r}}\right)}{q} \int_{0}^{L_{\mathrm{s}}} I\left(\lambda^{-1} q ; \lambda t\right) d t+\frac{\rho_{\mathrm{r}}^{2}\left[q L_{\mathrm{r}} \operatorname{Si}\left(q L_{\mathrm{r}}\right)+\cos \left(q L_{\mathrm{r}}\right)-1\right]}{q^{2}}\right]}{\left(3 L_{\mathrm{s}}+\rho_{\mathrm{r}} L_{\mathrm{r}}\right)^{2}}
$$

where $\rho_{\mathrm{r}}$ is the ratio of excess electron density per unit contour length for the rod arm to that for the wormlike arms; in this case $\rho_{\mathrm{r}}$ is assumed to be 3 . The particle scattering function having finite chain thickness can be estimated using eq 6 . If we assume $L_{\mathrm{r}}=11 \mathrm{~nm}, \rho_{\mathrm{r}}=3, L_{\mathrm{s}}=83 \times 0.33 \mathrm{~nm}, \lambda^{-1}=5 \mathrm{~nm}$ (or $4 \mathrm{~nm}$ at $50{ }^{\circ} \mathrm{C}$ ), and $d=0.5 \mathrm{~nm}$, the calculated particle scattering function (solid red line in Figure 6) is mostly fitted by the theoretical value for the wormlike star without the rod region, indicating that the rod region does not directly cause a significant difference in $P(q)$ for the current system. On the other hand, the estimated chain stiffness of the random coil region is roughly twice as large as the single chain estimated for some collagen model peptides. ${ }^{7}$ This is likely due to segment-segment repulsive interactions between side chains or between a side chain and the rod region. It should be noted that the intramolecular excluded-volume effects of each arm may not significantly affect $\left\langle S^{2}\right\rangle^{1 / 2}$ because the Kuhn segment number $\lambda L$ is estimated to be 14 when assuming $\lambda^{-1}=2 \mathrm{~nm}$ and furthermore the effect is only appreciable $\lambda L>50$ for most cases. ${ }^{34-35}$ Thus, the intramolecular repulsive force is more effective nearby the center of the star-like peptide, and the chain stiffness may depend on the contour point of the 
arm chain. This effect and the heterogeneity of repeating units may be the reason why the theoretical curves are slightly different from the experimental values at high temperatures.

On the other hand, the particle scattering function between $23{ }^{\circ} \mathrm{C}$ and $25^{\circ} \mathrm{C}$ cannot be explained by either the rodlike or the star-like chain models because of the transition temperature region. Assuming that only a negligibly small amount of partially loosened helix is present in solution and thus the all-ornone model is applicable, the particle scattering function $P_{\text {mixture }}(q)$ of the mixture of rodlike and starlike chains can be expressed as

$$
P_{\text {mixture }}(q)=F(T) P_{\text {cylinder }}(q)+9[1-F(T)]\left(\frac{2}{q d}\right)^{6}\left(\sin \frac{q d}{2}-\frac{q d}{2} \cos \frac{q d}{2}\right)^{2} P_{\text {heterostar }}(q)
$$

The theoretical $P_{\text {mixture }}(q)$ values at $F(T)=0.1$ and 0.3 estimated by circular dichroism as illustrated in Figure 5 fairly reproduce the experimental data at $25{ }^{\circ} \mathrm{C}$ and $23{ }^{\circ} \mathrm{C}$, respectively, suggesting that the scattering function for the current trimeric peptide can be explained by reasonable models including the conformational transition region.

\section{- CONCLUSIONS}

From SAXS data, below the transition temperature, the trimeric peptide behaves as a rigid rod in the aqueous buffer while the conformation changed to three-arm star like chain with a linking domain at high temperature. The gyration radius of the peptide molecule at high temperature is appreciably larger than that expected for the three-arm star of which each side chain has the same conformation as the denatured peptide. The estimated Kuhn segment length was $4.5 \mathrm{~nm} \pm 1 \mathrm{~nm}$ which is approximately twice larger than that for denatured peptide chains. ${ }^{7}$ This is likely due to the intramolecular interactions nearby the linking point since each arm does not have enough length to be regarded as Gaussian coil and furthermore the linking domain is still much larger than those for the coupling agents for the conventional star polymers ${ }^{36-37}$ of which the dimensional properties are mainly explained by the ZimmStockmayer equation for the Gaussian star chains. ${ }^{38}$

\section{- AUTHOR INFORMATION Corresponding Author \\ *E-mail: kterao@chem.sci.osaka-u.ac.jp,hpb@shcc.org \\ Notes}

The authors declare no competing financial interests.

\section{- ACKNOWLEDGMENTS}

The authors are grateful to Prof. Takahiro Sato in Osaka University for productive discussion and to Dr. Nobutaka Shimizu and Dr. Noriyuki Igarashi in KEK and Dr. Noboru Ohta in SPring-8 for SAXS measurements. The synchrotron radiation experiments were performed at the BL40B2 in SPring-8 with the approval of the Japan Synchrotron Radiation Research Institute (JASRI) (Proposal \#2012B1050) and at the BL-10C in KEK-PF under the approval of the Photon Factory Program Advisory Committee (\#2011G557). This work was partially supported by JSPS KAKENHI Grant No. 25410130.

\section{- REFERENCES}

1. Kratky, O.; Porod, G. Rontgenuntersuchung Geloster Fadenmolekule. Recl. Trav. Chim. PaysBas 1949, 68, 1106-1122.

2. Yamakawa, H. Helical Wormlike Chains in Polymer Solutions. Springer: Berlin, Germany, 1997. 3. Yamakawa, H. A New Framework of Polymer Solution Science. The Helical Wormlike Chain. Polym. J. 1999, 31, 109-119.

4. $\quad$ Norisuye, T. Semiflexible Polymers in Dilute-Solution. Prog. Polym. Sci. 1993, 18, 543-584. 
5. Nakamura, Y.; Norisuye, T. 2.02 - Polymer Properties in Solutions. In Polymer Science: A Comprehensive Reference, Editors-in-Chief: Krzysztof, M.; Martin, M., Eds. Elsevier: Amsterdam, 2012; pp 5-32.

6. Kameda, H.; Hirabayashi, K.; Wada, K.; Fukuyama, K. Mapping of Protein-Protein Interaction Sites in the Plant-Type [2Fe-2S] Ferredoxin. PLoS ONE 2011, 6, e21947.

7. Terao, K.; Mizuno, K.; Murashima, M.; Kita, Y.; Hongo, C.; Okuyama, K.; Norisuye, T.; Bächinger, H. P. Chain Dimensions and Hydration Behavior of Collagen Model Peptides in Aqueous Solution: [Glycyl-4(R)-hydroxyprolyl-4(R)-hydroxyproline](n), [Glycylprolyl-4(R)-hydroxyproline](n), and Some Related Model Peptides. Macromolecules 2008, 41, 7203-7210.

8. Kohn, J. E.; Millett, I. S.; Jacob, J.; Zagrovic, B.; Dillon, T. M.; Cingel, N.; Dothager, R. S.; Seifert, S.; Thiyagarajan, P.; Sosnick, T. R.; Hasan, M. Z.; Pande, V. S.; Ruczinski, I.; Doniach, S.; Plaxco, K. W. Random-Coil Behavior and the Dimensions of Chemically Unfolded Proteins. Proc. Natl. Acad. Sci. U. S. A. 2004, 101, 12491-6.

9. Decker, P. D. Etude en Solution Diluée de Polymères à Structure en "Peigne". Makromol. Chem. 1969, $125,136-160$.

10. Noda, I.; Horikawa, T.; Kato, T.; Fujimoto, T.; Nagasawa, M. Solution Properties of CombShaped Polystyrenes. Macromolecules 1970, 3, 795-799.

11. Candau, F.; Rempp, P. Morphological Study in Diluted Polystyrene Solution with Comb Structure. Eur. Polym. J. 1972, 8, 757-768.

12. Strazielle, C.; Herz, J. Synthesis and Physical-Chemistry of Branched Star-Shaped and CombLike Polystyrenes. Eur. Polym. J. 1977, 13, 223-233.

13. Terao, K.; Farmer, B. S.; Nakamura, Y.; Iatrou, H.; Hong, K. L.; Mays, J. W. Radius of Gyration of Polystyrene Combs and Centipedes in a Theta Solvent. Macromolecules 2005, 38, 1447-1450.

14. Boudko, S. P.; Engel, J.; Bächinger, H. P. Trimerization and Triple Helix Stabilization of the Collagen XIX NC2 Domain. J. Biol. Chem. 2008, 283, 34345-51.

15. Boudko, S. P.; Bächinger, H. P. The NC2 Domain of type IX Collagen Determines the Chain Register of the Triple Helix. J. Biol. Chem. 2012, 287, 44536-45.

16. Mizuno, K.; Boudko, S.; Engel, J.; Bächinger, H. P. Vascular Ehlers-Danlos syndrome mutations in type III collagen differently stall the triple helical folding. J. Biol. Chem. 2013, 288, 19166-76.

17. Fields, G. B.; Prockop, D. J. Perspectives on the Synthesis and Application of Triple-Helical, Collagen-Model Peptides. Biopolymers 1996, 40, 345-57.

18. Shikata, T.; Minakawa, A.; Okuyama, K. Structure, Dynamics, and Hydration of a Collagen Model Polypeptide, (L-prolyl-L-prolylglycyl)10, in Aqueous Media: A Chemical Equilibrium Analysis of Triple Helix-to-Single Coil Transition. J. Phys. Chem. B 2009, 113, 14504-14512.

19. Berry, G. C. Thermodynamic and Conformational Properties of Polystyrene .I. Light-Scattering Studies on Dilute Solutions of Linear Polystyrenes. J. Chem. Phys. 1966, 44, 4550-4564.

20. Glatter, O.; Kratky, O. Small Angle X-ray Scattering. Academic Press: London, 1982.

21. Terao, K.; Mays, J. W. On-Line Measurement of Molecular Weight and Radius of Gyration of Polystyrene in a Good Solvent and in a Theta Solvent Measured with a Two-Angle Light Scattering Detector. Eur. Polym. J. 2004, 40, 1623-1627.

22. Okumoto, M.; Nakamura, Y.; Norisuye, T.; Teramoto, A. Excluded-Volume Effects in Star Polymer Solutions: Four-Arm Star Polystyrene in Benzene. Macromolecules 1998, 31, 1615-1620.

23. Holtzer, A. Interpretation of the Angular Distribution of the Light Scattered by a Polydisperse System of Rods. J. Polym. Sci. 1955, 17, 432-434.

24. Pedersen, J. S.; Schurtenberger, P. Cross-Section Structure of Cylindrical and Polymer-Like Micelles from Small-Angle Scattering Data. I. Test of Analysis Methods. J. Appl. Crystallogr. 1996, 29 PART 6, 646-661.

25. Nakamura, Y.; Norisuye, T. Scattering Function for Wormlike Chains with Finite Thickness. $J$. Polym. Sci., Part. B: Polym. Phys. 2004, 42, 1398-1407.

26. Huber, K.; Burchard, W. Scattering Behavior of Wormlike Star Macromolecules. Macromolecules 1989, 22, 3332-3336. 
27. Nakamura, Y.; Norisuye, T. In Soft-Matter Characterization, Borsali, R. P., R., Ed. Springer: Berlin, 2008; Vol. 1, pp 236-286.

28. Burchard, W.; Kajiwara, K. The Statistics of Stiff Chain Molecules. I. The Particle Scattering Factor. Proc. R. Soc. London, Ser. A 1970, 316, 185-199.

29. Mansfield, M. L.; Stockmayer, W. H. Unperturbed Dimensions of Wormlike Stars. Macromolecules 1980, 13, 1713-1715.

30. Terao, K.; Terao, Y.; Teramoto, A.; Nakamura, N.; Fujiki, M.; Sato, T. Temperature and Solvent Dependence of Stiffness of Poly\{n-hexyl-[(S)-3-methylpentyl]silylene\} in Dilute Solutions. Macromolecules 2001, 34, 4519-4525.

31. Yanai, H.; Sato, T. Local Conformation of the Cellulosic Chain in Solution. Polym. J. 2006, 38, 226-233.

32. Terao, K.; Morihana, N.; Ichikawa, H. Solution SAXS Measurements over a Wide Temperature Range to Determine the Unperturbed Chain Dimensions of Polystyrene and a Cyclic Amylose Derivative. Polym. J. 2014, 46, 155-159.

33. Terao, K.; Kanenaga, R.; Sato, T.; Mizuno, K.; Bächinger, H. P. Complex Formation of Collagen Model Peptides with Polyelectrolytes and Stabilization of the Triple Helical Structure. Macromolecules 2012, 45, 392-400.

34. Norisuye, T.; Fujita, H. Excluded-Volume Effects in Dilute Polymer Solutions. XIII. Effects of Chain Stiffness. Polym. J. 1982, 14, 143-147.

35. Norisuye, T.; Tsuboi, A.; Teramoto, A. Remarks on Excluded-Volume Effects in Semiflexible Polymer Solutions. Polym. J. 1996, 28, 357-361.

36. Roovers, J. E. L.; Bywater, S. Preparation and Characterization of Four-Branched Star Polystyrene. Macromolecules 1972, 5, 384-388.

37. Douglas, J. F.; Roovers, J.; Freed, K. F. Characterization of Branching Architecture through Universal Ratios of Polymer-Solution Properties. Macromolecules 1990, 23, 4168-4180.

38. Zimm, B. H.; Stockmayer, W. H. The Dimensions of Chain Molecules Containing Branches and Rings. J. Chem. Phys. 1949, 17, 1301-1314. 
For Table of Contents Use Only

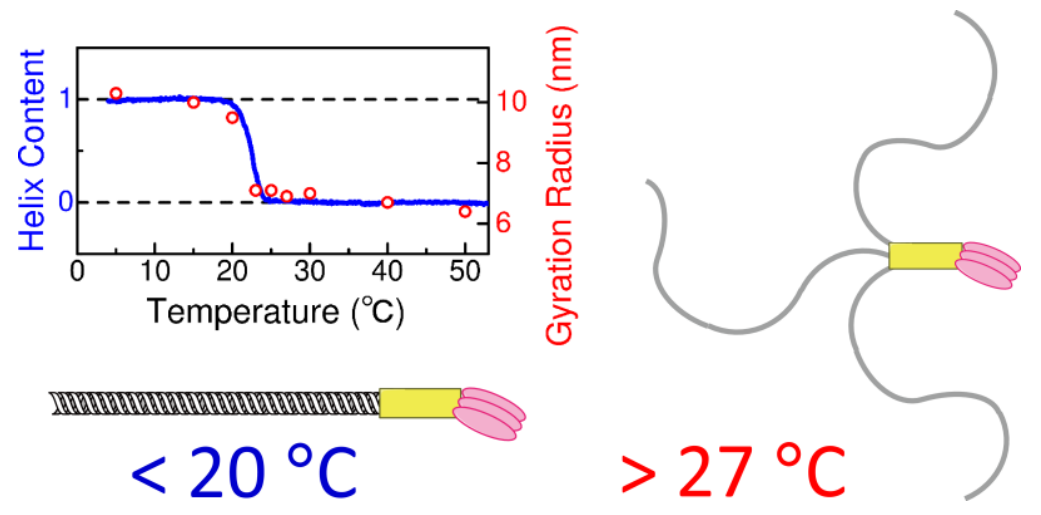

Conformational Change from Rigid Rod to Star: A Triple Helical Peptide with a Linker Domain at One End

Ken Terao,* Kazunori Mizuno, and Hans Peter Bächinger* 